Article

\title{
The First Pi2 Pulsation Observed by China Seismo-Electromagnetic Satellite
}

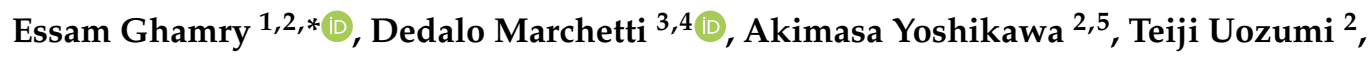 \\ Angelo De Santis ${ }^{4}\left(\mathbb{D}\right.$, Loredana Perrone ${ }^{4}\left(\mathbb{D}\right.$, Xuhui Shen ${ }^{6}$ and Adel Fathy ${ }^{7}$ \\ 1 National Research Institute of Astronomy and Geophysics, Helwan 11421, Cairo, Egypt \\ 2 International Center for Space Weather Science and Education, Kyushu University, Fukuoka 819-0395, Japan; \\ yoshikawa.akimasa.254@m.kyushu-u.ac.jp (A.Y.); uozumi.teiji.935@m.kyushu-u.ac.jp (T.U.) \\ 3 School of Remote Sensing and Geomatics Engineering, Nanjing University of Information Science and \\ Technology, Nanjing 210044, China; dedalo.marchetti@ingv.it \\ 4 INGV Istituto Nazionale di Geofisica e Vulcanologia, 00143 Rome, Italy; angelo.desantis@ingv.it (A.D.S.); \\ loredana.perrone@ingv.it (L.P.) \\ 5 Department of Earth and Planetary Science, Kyushu University, Fukuoka 819-0395, Japan \\ 6 Institute of Crustal Dynamics, China Earthquake Administration, Beijing 100085, China; Shenxh@seis.ac.cn \\ 7 Physics Department, Faculty of Science, Fayoum University, Fayoum 63514, Egypt; afa05@fayoum.edu.eg \\ * Correspondence: essamgh@nriag.sci.eg
}

Received: 14 June 2020; Accepted: 13 July 2020; Published: 17 July 2020

check for updates

\begin{abstract}
On 2 February 2018, the China Seismo-Electromagnetic Satellite (CSES) ZhangHeng 01 (ZH-01) was successfully launched, carrying on board, in addition to a suite of plasma and particle physics instruments, a high precision magnetometer package (HPM), able to observe the ultra-low frequency (ULF) waves. In this paper, a night time Pi2 pulsation observed by CSES is reported for the first time. This Pi2 event occurred on 3 September 2018, and began at 14:30 UT (02:37 magnetic local time), when the satellite was in the southern hemisphere between -49 and -13 magnetic latitude (MLAT). Kakioka (KAK) ground station in Japan detected the same Pi2 between 14:30-14:42 UT (23:30-23:42 local time). The Pi2 oscillations in the compressional, toroidal, and poloidal components at the CSES satellite and the H-component at the KAK station are investigated by estimating coherence, amplitude, and cross-phase. We noticed a high degree of similarity between the Pi2 event in the horizontal component at KAK and the ionospheric fluctuations in the compressional component at CSES. This high correlation indicated the magnetospheric source of the Pi2 event. In addition, $\mathrm{Pi} 2$ is exhibited clearly in the $\delta$ By component at CSES, which is highly correlated with the ground $\mathrm{H}$ component, so the Pi2 event could be explained by the Substorm Current Wedge (SCW). This interpretation is further confirmed by checking the compressional component of Van Allen Probe (VAP) B satellite inside the plasmasphere, which, for the first time, gives observational support for an earlier model. This ULF wave observation shows the consistency and reliability of the high precision magnetometer (HPM) equipped by two fluxgate magnetometers (FGM1 and FGM2) onboard CSES.
\end{abstract}

Keywords: CSES satellite; VAP mission; Pi2 pulsation; topside ionosphere

\section{Introduction}

Pi2 magnetic pulsation is an impulsive nightside ultra-low frequency (ULF) wave and it is considered a sensitive indicator to the onset of the geomagnetic substorms within low- and mid-latitudinal regions. The presence of Pi2s with the substorm onset makes it as an imperative intermedia for understanding the electrodynamic processes occurring in the coupling between magnetospheric and ionospheric regions. The frequency range of this wave is $6.6-25 \mathrm{mHz}$, i.e., a period of 40-150 s, with an amplitude of 0.2-2.3 nT. Pi2 pulsations have a common period and can be 
noticed on the ground over wide regions, which vary from high to low latitudes with different spectral contents over a wide Local Time (LT) [1]. Although Pi2 is a common nighttime phenomenon, daytime Pi2 can be observed as well with similar periods and phases [2,3], and with an enhancement of its amplitude at the dip equator [4].

The mechanism of the Pi2 has not been firmly established but it suggests that it has different source for different latitudes [5]. At high latitudes, Alfvén waves are commonly invoked as the source of Pi2 on the ground, which is known as the field line resonance (FLR) and is linked with Ffield-Aligned Currents (FAC). However, at the mid and low latitudes, a plasmaspheric cavity resonance is presumably a common source of Pi2 waves [6]; this phenomenon is commonly known as a fast mode wave enclosed inside the plasmasphere [7-9].

The authors of [10] suggested a Pi2 model connected with the substorm current wedge (SCW) structure. They proposed that azimuthal magnetic perturbation of Pi2 can be generated by the field-aligned currents (FACs) in the pulses of SCW. The authors of [11-13] investigated global high-correlation Pi2 events on the night side region.

The delay time of Pi2 magnetic micro-pulsation in the high-latitude $\mathrm{H}$ component exhibits a significant delay $(\mathrm{T}<\sim 100 \mathrm{~s})$ from $\mathrm{Pi} 2$ in the $\mathrm{H}$ component at a low-latitude station, as reported by [11-15]. These authors also found that the delay time of Pi2 in the D component at a high-latitude exhibits fewer seconds to Pi2 than at the $\mathrm{H}$ component in a low-latitude station. Based on Pi2 observations at ground stations, the model in [11], which focused on studying the high-latitude Pi2 as observed in the $\mathrm{H}$ and $\mathrm{D}$ components, is compatible with the model in [10]. One of the wave elements that likely exists in global high-correlation Pi2 waves, according to [11,13], is the SCW oscillations, which mainly occurred in D component in the low, middle, and high-latitudinal Pi2 regions. The study reported in [16] for the Pi2 pulsation, observed near terminators, clarifies the contribution of the night side SCW on this pulsation.

In the last few decades, Low Earth Orbit (LEO) satellites in the upper ionosphere have given some unique opportunities and a lot of information to demonstrate the effect of the ionosphere on ULF waves propagating from the magnetosphere [17]. In ULF studies from LEO satellites, one of the prime challenges is the rapid movement of the spacecraft so the lower frequencies of the ULF waves $(<10 \mathrm{mHz})$ would be masked by the Doppler shift.

There are several studies of ULF waves in the Pc3 and Pi2 frequency ranges $(22-100 \mathrm{mHz}$ and $6.7-25 \mathrm{mHz}$, respectively) that have been investigated using LEO satellite observations such as the Swarm three-satellite mission in the topside ionosphere $[18,19]$. The authors of [20] elucidated a Pi2 wave seen by LEO satellite, called UARS, and on the ground by the low-latitude Kakioka (KAK) station. They demonstrated a similarity between the Pi2 event at a low-latitude region in the horizontal $\mathrm{H}$ component and ionospheric perturbations in the compressional Bz component. Using the CHAMP satellite, the authors of [21], in their comparison between the Pi2 waves detected at a low-latitudinal ground station, showed that the $\mathrm{Bx}$ and $\mathrm{Bz}$ oscillations have a good similarity with the horizontal $\mathrm{H}$ component, but the Bx and Bz perturbations were in phase and out of phase in the Northern Hemisphere and Southern Hemisphere, respectively. The same authors concluded that the observations give more support for a plasmaspheric cavity mode. They showed that night side Pi2 pulsation in the azimuthal component seems to have a good correlation between the ground station and the topside ionosphere. The authors of [22] used data acquired from the LEO satellite called Ørsted and the KAK ground station and made an analysis of Pi2 magnetic micro-pulsations; they found a similarity between the $\mathrm{Bz}$ component of Pi2 pulsations at Ørsted and the $\mathrm{H}$ component on the ground, but no correlation found in the Bx and By components, with the ground observations at $\mathrm{H}$.

China Seismo-Electromagnetic Satellite (CSES) has been already useful to study several phenomena, including space weather events like the geomagnetic storm of the 26 August 2018 [23-25], and the possible response of the ionosphere to a preparation phase of the earthquakes as the case study of the M7.5 Indonesia 28 September 2018, event [26], or other shallow and deep earthquakes with a magnitude between 7.1 and 8.1 [27]. Moreover, the satellite can give an important contribution to the 
monitor of the geomagnetic field and its variations and pulsations (as it will be investigated in this work) to better understand the physics of the ionosphere, the Van Allen belts, and more [28].

To the best of authors' knowledge, this is the first investigation of Pi2 pulsation made using the CSES satellite. Few studies have addressed the observation of global high-correlation Pi2 on the ground and in the ionosphere and magnetosphere. The authors of [29] show the formation and time evolution of a three-dimensional (3-D) oscillatory current system in the SCW. Our results strongly support the result of [29] using in situ observation of Pi2 in the magnetosphere. Pi2 analysis confirms the consistency and reliability of the high precision magnetometer (HPM) equipped by two fluxgate magnetometers (FGM1 and FGM2) onboard CSES. We use the KAK low-latitude ground station as the reference signal relative to those spectral intensities, coherence, and phase of the ionospheric magnetic field observed at the CSES and Van Allen Probe (VAP) satellites. The paper can be organized as follows. In Section 2, all data sets are described. The observations are presented in Section 3. In Section 4 we discuss the results. Section 5 presents the conclusions of this paper.

\section{Data Sets}

\subsection{CSES Satellite}

The first CSES is also called Zhangheng (ZH-1) in honor of Zhang Heng, a Chinese scientist who lived from $\mathrm{AD} 78$ to 139 and who invented the first seismoscope. The satellite, managed by the Chinese Space Agency, China Earthquake Administration, and Italian Space Agency, has been working for over two years since its launch on 2 February 2018, and it is still in orbit and in nominal working conditions. The main scope of the mission is to search for perturbations of the ionosphere and to study their possible correlation with the occurrence of seismic events. To achieve this goal, the satellite has been equipped with nine payloads that monitor the ionospheric magnetic and electric field, two-particle detectors, and other instruments to analyze the plasma, like LAP (Langmuir Probes) and PAP (Plasma Analyzer Package) to determine the electron density, temperature, and which ionized elements are present in the orbital environment.

CSES-01 is the first satellite of a constellation of at least five satellites, and China and Italy are presently building the second one, i.e., CSES-02. CSES-01 works in two modes: burst and survey, with different parameters and sampling rates. The satellite is set to work in burst mode over China and in a seismic belt around the world, and in survey mode in other regions. The data are downloaded from China when the satellite passes over the country. The orbit is quasi polar and Sun-synchronous, with a coverage return time of exactly five days.

To measure the magnetic field, CSES has been equipped with two fluxgate magnetometers (HPM1 and HPM2), placed on two orthogonal booms, which provide the orientation of the magnetic field while an absolute scalar magnetometer allows us to determine the intensity of the same field and calibrate the fluxgates. These instruments form the High Precision Magnetometer (HPM) instrument. The data are sampled at $60 \mathrm{~Hz}$ (however, we analyzed them at $1 \mathrm{~Hz}$ ). The orientation of the spacecraft is checked by two star-cameras placed on the satellite body. The electron density and electron temperature are measured by a couple of Langmuir probes. An Electric Field Detector (EFD) placed at the end of another boom is dedicated to measuring the electric field vector. To detect possible particles emitted from the active faults, the satellite has been provided with two-particle detectors: The Low Energy Particle Detector and the High Energy Particle Detector; the latter detector has been designed and assembled in Italy by the Italian National Institute of Nuclear Physics (INFN).

The data are elaborated by the CSES team in four levels, starting from the raw level. In this study we processed the Level2, which is the calibrated data reported in the Earth Reference System. The data have been downloaded from the CSES portal (www.leos.ac.cn) where the data are available after a free registration.

CSES data are provided in the WSG84 reference system and coordinates. This reference system is defined in the Earth center with the $\mathrm{x}-\mathrm{y}$ plane as the equatorial one, where $\mathrm{X}$ points toward the 
Greenwich meridian, $\mathrm{Z}$ is parallel to the Earth's rotational axis, and $\mathrm{Y}$ is orthogonal forming a right-hand reference system. The origin of the reference system is then translated to the satellite position. To report the magnetic signal to the commonly used NEC frame (i.e., the one used by Swarm satellites), a rotation has been applied. The new coordinates have been calculated by two rotation matrices following the next equation:

$$
\left|\begin{array}{c}
B_{X} \\
B_{Y} \\
B_{Z}
\end{array}\right|=-1 \cdot\left|\begin{array}{ccc}
\cos (180-\lambda) & 0 & \sin (180-\lambda) \\
0 & 1 & 0 \\
-\sin (180-\lambda) & 0 & \cos (180-\lambda)
\end{array}\right| \cdot\left|\begin{array}{ccc}
\cos (180-\varphi) & -\sin (180-\varphi) & 0 \\
\sin (180-\varphi) & \cos (180-\varphi) & 0 \\
0 & 0 & 1
\end{array}\right| \cdot\left|\begin{array}{c}
B_{X(C S E S)} \\
B_{Y(\text { CSES })} \\
B_{Z(C S E S)}
\end{array}\right|
$$

where $\lambda$ and $\varphi$ are the geographical latitude and longitude of the CSES satellite at the acquisition time. As the CSES measures the total magnetic field (including the internal field, crustal field, and external field), we have used the CHAOS-6 model [30] of Earth's geomagnetic field, which was developed using more than 6.5 years of high-precision geomagnetic measurements from the Swarm three satellites, to retrieve the external ionospheric component. The residual fields, obtained from this model, are then transformed to Mean-Field Aligned (MFA) coordinates, poloidal, and toroidal components in the topside ionosphere.

\subsection{VAP Mission}

The twin VAP mission was launched on 30 August 2012, by NASA for its Living with a Star program. The VAP mission has two near-equatorial orbit spacecrafts (VAP-A and VAP-B). Both VAPs, with apogee near $\mathrm{L} \sim 6$, contain several sensors prepared to investigate the Earth's radiation medium [31]. The triaxial fluxgate magnetometers onboard the two satellites are qualified to measure 64 vectors per second [32].

We used Electric and Magnetic Field Instrument Suite and Integrated Science (EMFISIS) [32] to get $1 \mathrm{~Hz}$ data of the magnetic field. The EMFISIS magnetic data are rotated from the GSM coordinates into mean field-aligned (MFA) coordinates. This decomposition allows the dominant magnetic field wave polarization to be determined as toroidal (azimuthal), poloidal (radial), or compressional (parallel). In this system, the Bx is outward, perpendicular to the averaged magnetic field; By is eastward, perpendicular to the averaged magnetic field; and Bz is northward, along the averaged magnetic field.

\subsection{KAK Geomagnetic Observatory}

We used one-second resolution data from the low-latitude KAK geomagnetic observatory in Japan to examine Pi2 magnetic pulsations as detected on the ground. The geographic latitude, geographic longitude, and magnetic latitude of the KAK is $36.23^{\circ} \mathrm{N}, 140.18^{\circ} \mathrm{E}$, and $27.18^{\circ}$, respectively. The KAK $\mathrm{L}$-value $=1.31$ and its local time $=$ universal time $+9 \mathrm{~h}$.

\subsection{Supermag Auroral Electrojet Index (SML)}

We used 1 min data from the SML index to identify the onset of the substorm. The SML index is the equivalent of the AL index as identified from SuperMAG derived auroral electrojet indices. SuperMAG is a worldwide collaboration of organizations, and the derived indices are determined from approximately 110 stations. The authors of $[33,34]$ described the substorm identification technique.

\section{Observations}

\subsection{Pi2 Event at KAK and CSES}

Figure 1a shows the geomagnetic activity, represented by the SuperMag auroral electrojet SML index, and Figure $1 \mathrm{~b}$ shows the low-latitude magnetic field variations (H component) observed by the KAK station in Japan. 


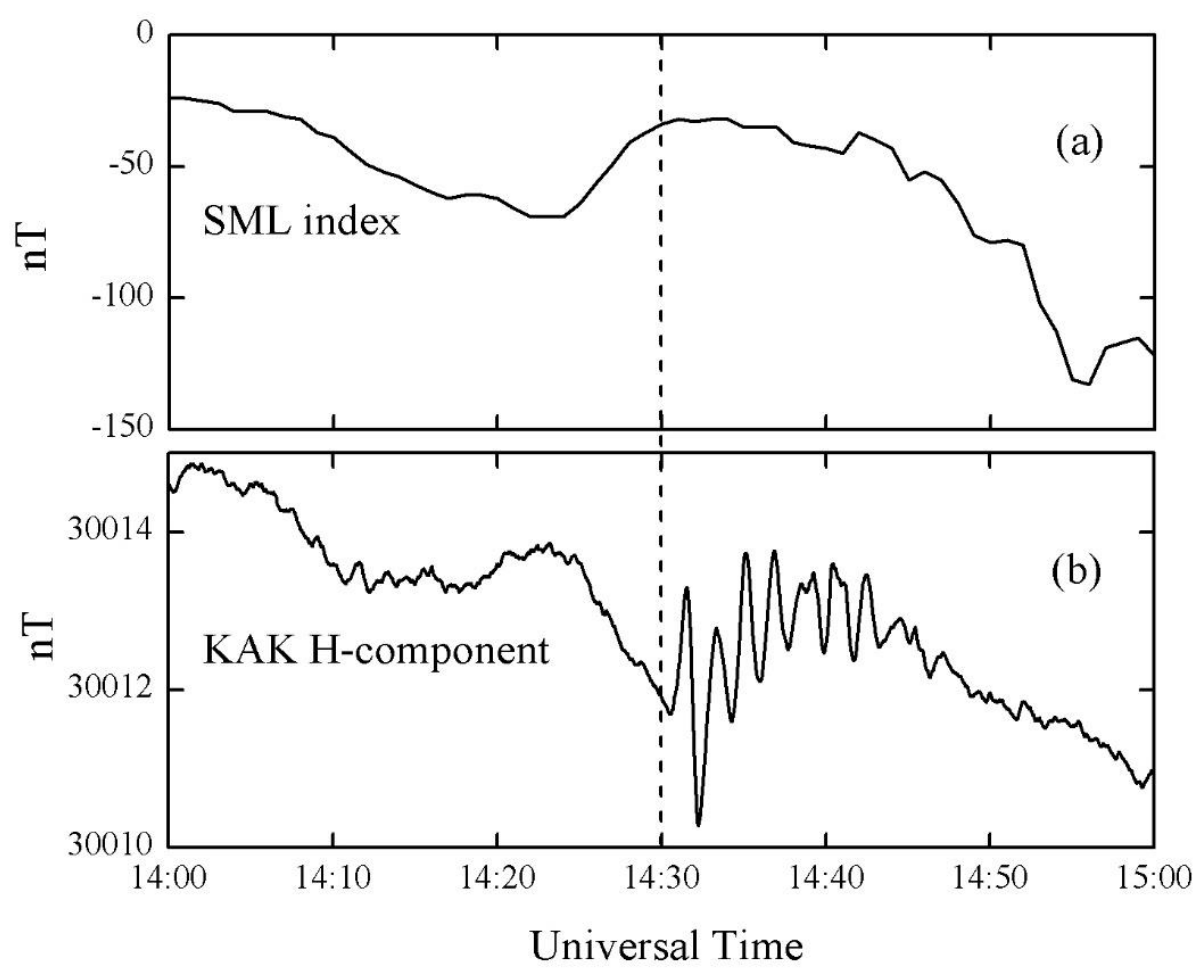

Figure 1. (a) SuperMag auroral electrojet index (SML) and (b) low-latitude magnetic field variations (H component) represented by Kakioka (KAK) station. The vertical dashed line indicates the onset time of Pi2 event.

The Pi2 pulsation occurred from 14:30 to 14:44 universal time (UT) on 3 September 2018, where the KAK was in the premidnight (23:30 LT). During the time interval 14:30-14:40 UT, which was subjected to detailed waveform analysis, the CSES satellite was in the southern hemisphere, moving from $-49.4^{\circ}$ to $-6^{\circ}$ magnetic latitude (MLAT). At that time, CSES was orbiting in the postmidnight at 02:37 magnetic local time (MLT). Both the KAK observatory and the CSES spacecraft were near and within $2.5 \mathrm{~h}$ of local time from each other. The magnetic data from the simultaneous availability of CSES and KAK give an opportunity to study, for the first time, the amplitude and phase of the Pi2 pulsation in the ionospheric magnetic field fluctuations at the CSES altitude. We examine the relationship between the $\mathrm{Pi} 2$ magnetic oscillation in the topside ionosphere and the Pi2 pulsations at a low-latitude region on the ground.

Figure 2a shows the time series of $\mathrm{KAK} \delta \mathrm{H}$ while Figure $2 \mathrm{~b}$ shows the $\delta \mathrm{Bx}, \delta \mathrm{By}$, and $\delta \mathrm{Bz}$ oscillations observed at the CSES satellite. The zero-phase band pass filter $(6.6-25 \mathrm{mHz})$ time series demonstrates that the Pi2 oscillates in all three components at the CSES satellite. The vertical dashed lines point out the crests of the $\delta \mathrm{H}$ component. Figure $2 \mathrm{c}$ shows the magnitude scalogram of the compressional component of the CSES.

First, we note that the KAK $\delta \mathrm{H}$ displayed seven cycles of a quasiperiodic fluctuation starting at 14:30 UT. CSES sees the same seven cycles in all magnetic field components. The waveform of the magnetic field in $\delta \mathrm{H}$ at KAK is very similar to $\delta \mathrm{Bz}$ at CSES without significant phase delay; however, the amplitude of KAK is larger than $\delta \mathrm{Bz}$ by a factor of $\sim 3$. This identical waveform reordered both at the ground and in the ionosphere indicates that these oscillations are caused by a common source mechanism. At CSES, $\delta \mathrm{Bz}$ and $\delta \mathrm{Bx}$ oscillate exactly in phase for the entire Pi2 interval and their amplitudes are similar. The fluctuations in CSES $\delta$ By and their waveform/period seem to match $\delta \mathrm{H}$ with small phase delay. 

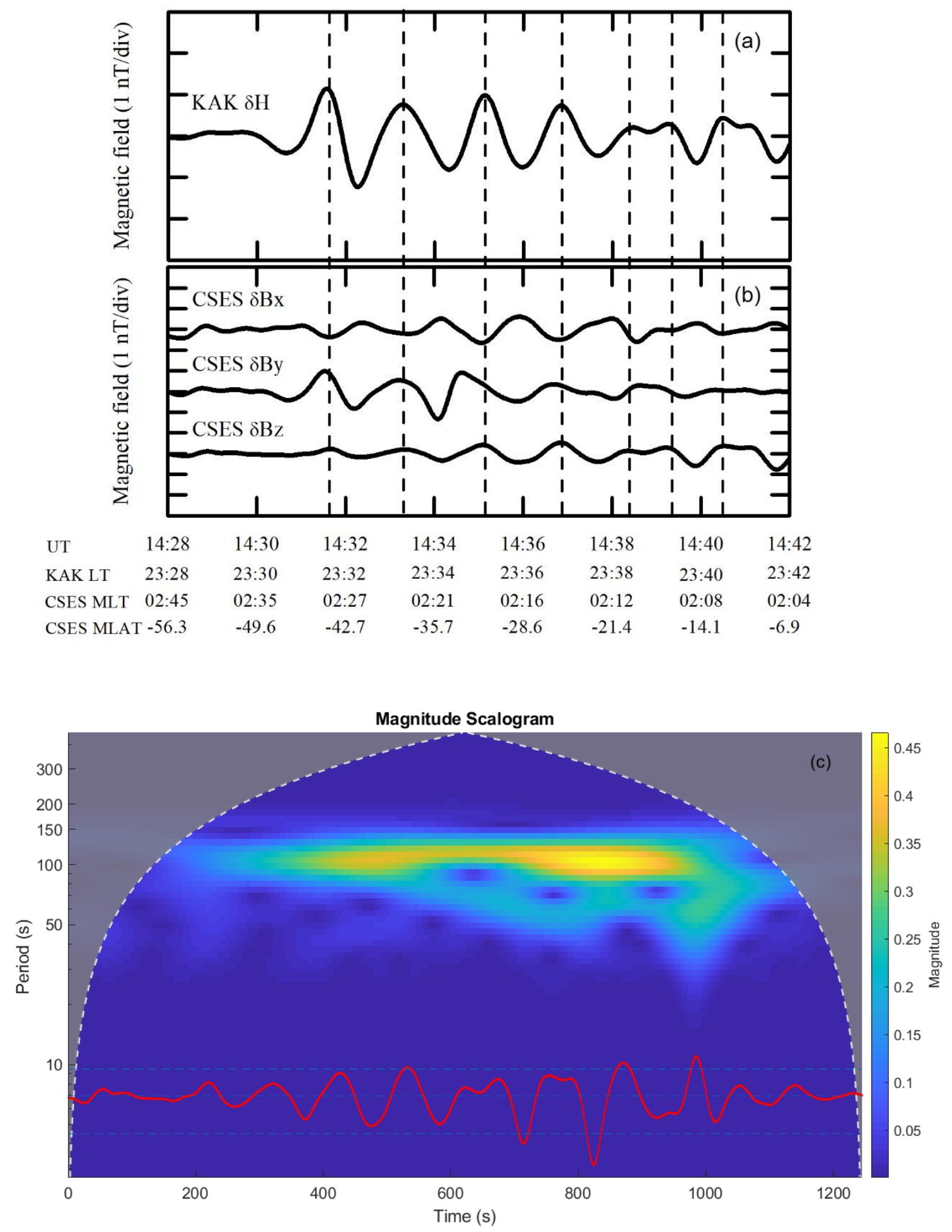

Figure 2. (a) shows $\mathrm{KAK} \delta \mathrm{H}$; (b) represents $\delta \mathrm{Bx}, \delta \mathrm{By}$, and $\delta \mathrm{Bz}$ oscillations observed at the China Seismo-electromagnetic satellite (CSES) satellite. MLAT denotes magnetic latitude, MLT stands for magnetic local time, and (c) is the magnitude scalogram of the compressional component of CSES. The original signal is reported as a red line at (c) while the light blue dashed lines represent $-0.5,0.0$, and $+0.50 \mathrm{nT}$, respectively. The vertical dashed lines at $(\mathbf{a}, \mathbf{b})$ indicate the crests of KAK $\delta \mathrm{H}$ component.

To confirm the similarity between KAK on the ground and CSES in the topside ionosphere, spectral dissection in the frequency domain was performed. Figure 3 shows the time series and spectral 
properties of Pi2 observed by KAK and CSES during the 10 min interval of 14:30-14:40 UT. Note that when the coherence was higher than 0.6 , then the cross phase was plotted.

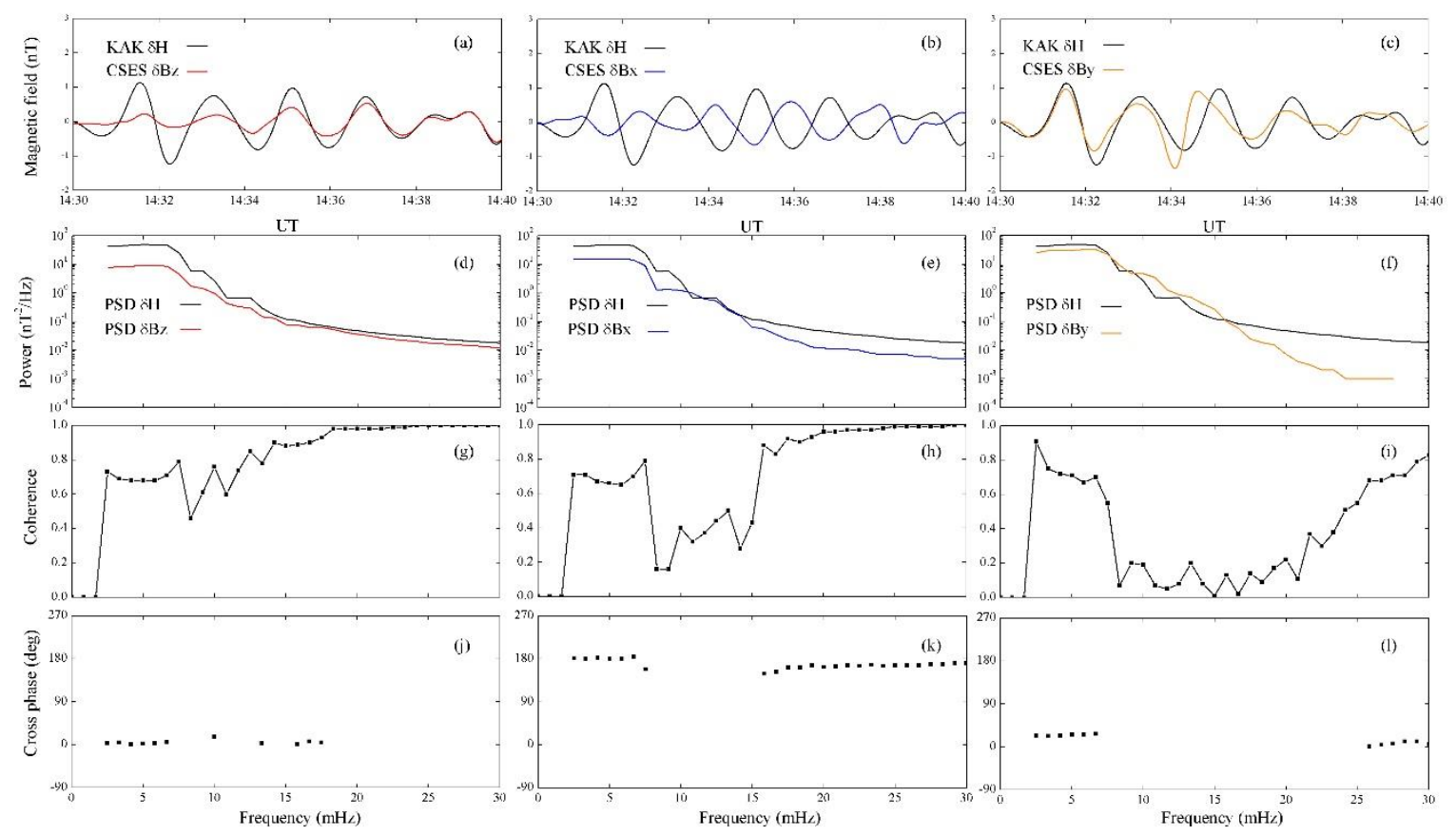

Figure 3. (a-c) Pi2 time series of the KAK ( $\delta \mathrm{H}$ component) and the CSES ( $\delta \mathrm{Bz}, \delta \mathrm{Bx}$, and $\delta \mathrm{By}$ components). The power density, coherence, and phase difference between each component of CSES $(\delta \mathrm{Bz}, \delta \mathrm{Bx}$, and $\delta$ By) and $\mathrm{KAK}(\delta \mathrm{H}$ component $)$ are presented in $(\mathbf{d}-\mathbf{f}),(\mathbf{g}-\mathbf{i})$, and $(\mathbf{j}-\mathbf{1})$, respectively.

As expected from Figure 2, the spectral dissection for the $\delta \mathrm{H}$ and $\delta \mathrm{Bz}$ components (Figure $3 \mathrm{~d}$ ) shows a dominant spectral enhancement centered at around $6.5-7.5 \mathrm{mHz}$ with a similar spectral shape, but the $\delta \mathrm{Bz}$ power spectrum is smaller than that of $\delta \mathrm{H}$. The $\delta \mathrm{Bz}-\delta \mathrm{H}$ coherence (Figure $3 \mathrm{~g}$ ) is more than 0.6 , and the cross phase is near to $0^{\circ}$ (Figure $3 \mathrm{j}$ ).

The $\delta \mathrm{Bx}$ spectral dissection (Figure 3e) also points out an enhancement at $\sim 6.5 \mathrm{mHz}$, and the intended $\delta \mathrm{Bx}-\delta \mathrm{H}$ coherence (Figure $3 \mathrm{~h}$ ), estimated for 10 minutes, is more than 0.6 with a phase delay of $180^{\circ}$ (Figure 3k). Figure $3 \mathrm{f}$ shows that the power spectrum of $\delta \mathrm{By}$ is similar to that of $\delta \mathrm{Bz}$ near $6.5 \mathrm{mHz}$, and the $\delta$ By power is quite similar to the $\delta \mathrm{H}$ power. The $\delta \mathrm{By}-\delta \mathrm{H}$ calculated coherence (Figure 3i) shows a higher spectrum than 0.6 at $\sim 6-7.5 \mathrm{mHz}$, but quickly reduces to less than 0.2 at frequencies of $\sim 8-25 \mathrm{mHz}$.

\subsection{VAP Observations}

Here we will examine the Pi2 event using data from the VAP magnetospheric mission. During the time interval of the Pi2 pulsation (14:30-14:40 UT), VAP-A and VAP-B satellites were located in the night side (01:49 and 22:06 MLT, respectively). The radial distances at the onset of the substorm were 4.62 RE and 5.35 RE for VAP-A and VAP-B, respectively. Both the VAP-A and VAP-B orbits were visualized onto the solar magnetic $x-y$ plane for the $6 \mathrm{~h}$ intervals, and they are shown in Figure $4 a, b$, respectively. To examine if both satellites are inside or outside the plasmasphere, we checked the electron number density (Ne). Figure $4 \mathrm{c}, \mathrm{d}$ show the $\mathrm{Ne}$ as being calculated from the frequency of the upper hybrid waves identified by the VAP-A and VAP-B satellites from 13:00 UT to 19:00 UT. 

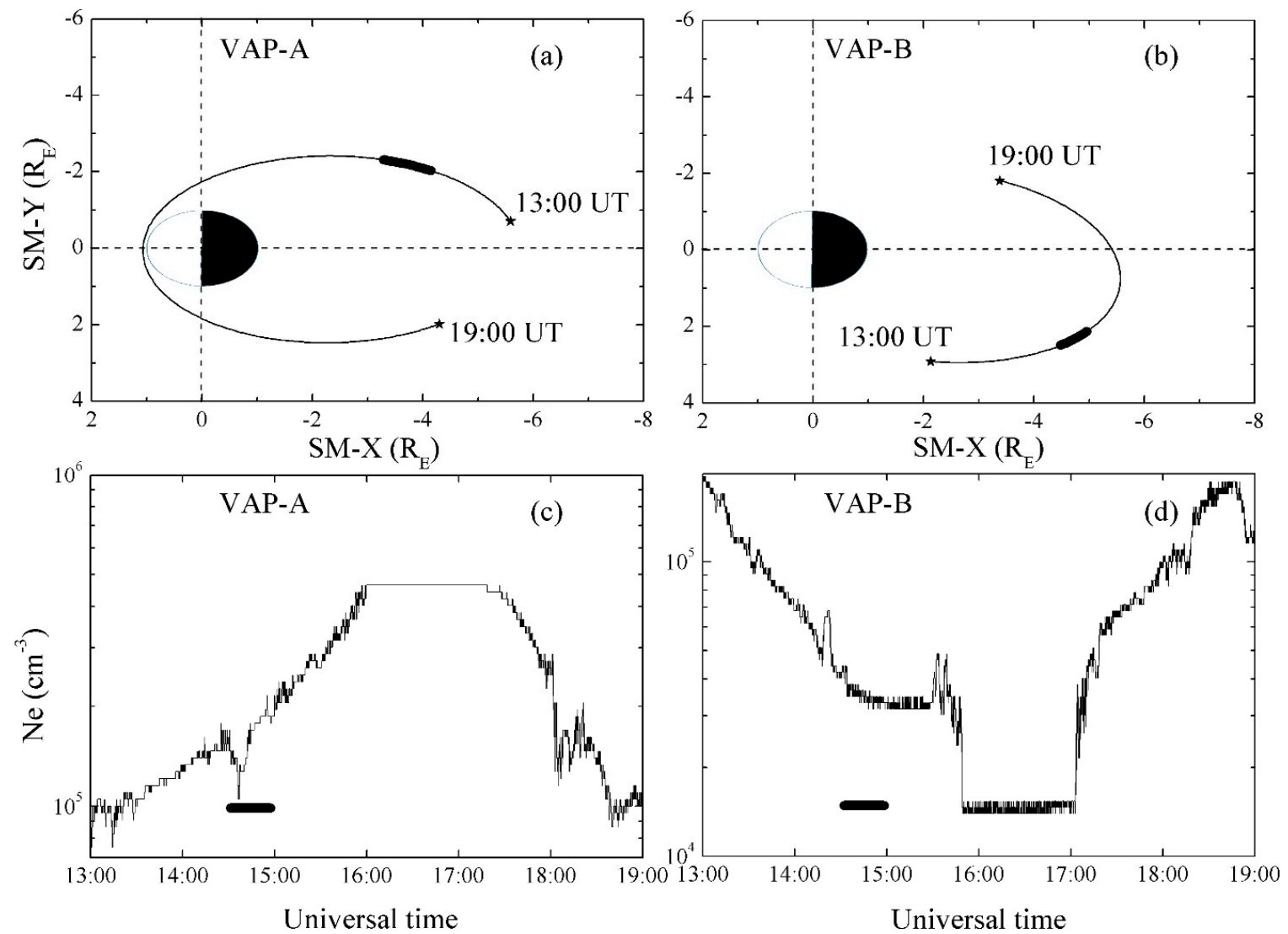

Figure 4. Van Allen Probe A (VAP-A) orbit (a) and Van Allen Probe B (VAP-B) orbit (b) visualized onto the solar magnetic $\mathrm{x}-\mathrm{y}$ plane for six-hour periods. (c,d) depict the electron density identified by VAP-A and VAP-B, respectively. Thick curved lines in $(\mathbf{a}, \mathbf{b})$ and thick bars in $(\mathbf{c}, \mathbf{d})$ highlight the time period of 14:30-15:00 UT.

At the onset time of the Pi2, VAP-A was near the inner edge of the plasmapause. Thus, the Pi2 event occurred when VAP-A was inside the plasmasphere. VAP-B was at first in the plasmasphere from 13:00 UT to $\sim 15: 50 \mathrm{UT}$, and after that it ran across a severe Ne decrease from $\sim 15 \mathrm{~cm}^{-3}$ to $\sim 2 \mathrm{~cm}^{-3}$ at $\mathrm{L}=\sim 6.2$ before midnight $(\sim 23: 00 \mathrm{MLT})$. This decrease in density is attributed to an outbound plasmapause crossing. VAP-B ran across an abrupt Ne increase from $\sim 2 \mathrm{~cm}^{-3}$ to $\sim 13 \mathrm{~cm}^{-3}$, which is due to an inbound plasmapause crossing, at about 17:03 UT $(\mathrm{L}=\sim 5.9$ and MLT $=23: 55)$. From this Ne information, we can emphasize that VAP-B was inside the plasmasphere when the Pi2 pulsation was observed at the ground station.

Figure $5 \mathrm{a}-\mathrm{c}$ show the Pi2 pulsations at KAK $\delta \mathrm{H}$ and the places of CSES, VAP-A, and VAP-B in a dipole-based coordinate system (MLAT and MLT) during 14:00-15:00 UT. We indicate the onset time of the Pi2 pulsations by the vertical dashed line as identified from a visual check of the KAK $\delta \mathrm{H}$. 


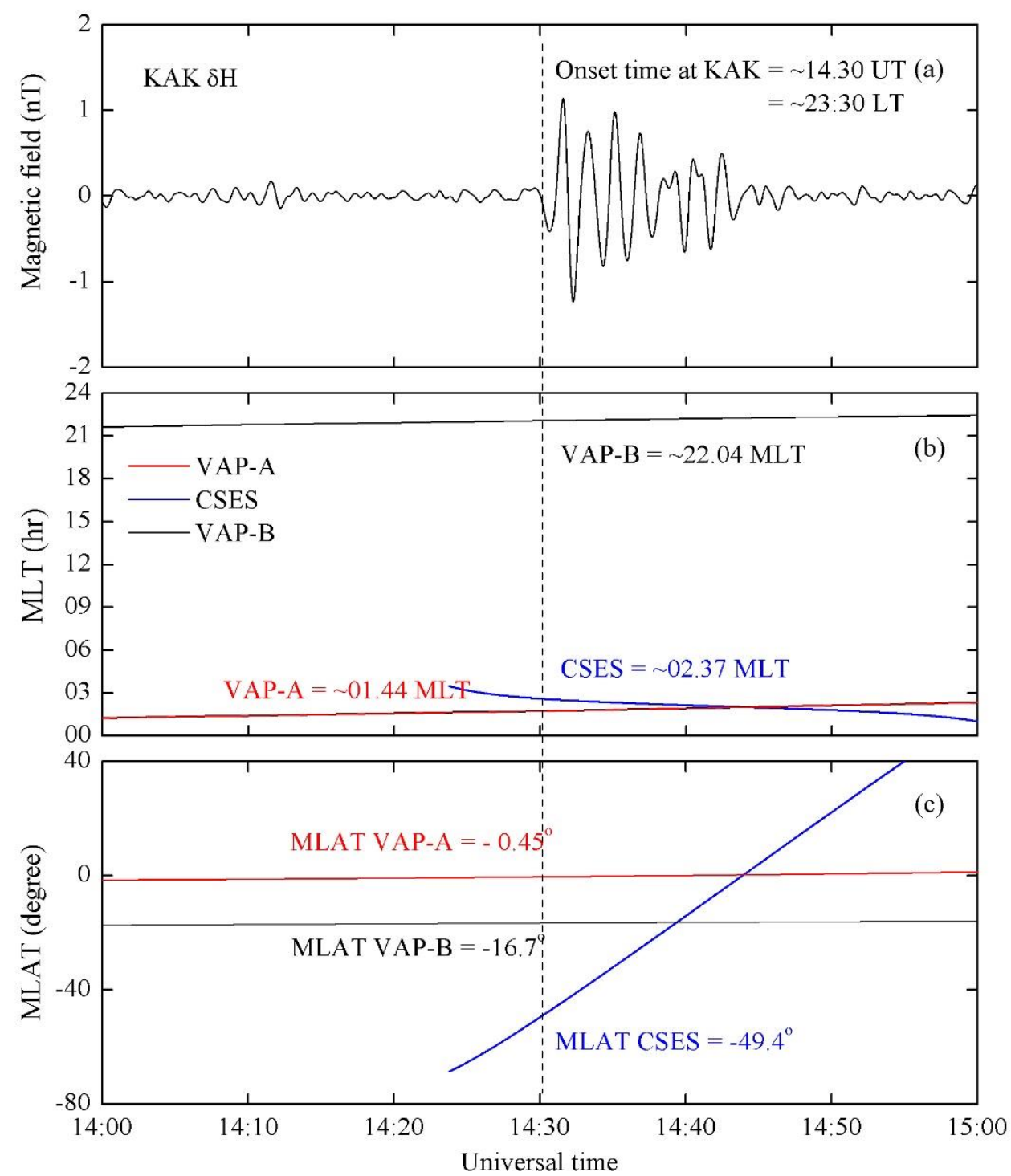

Figure 5. Pi2 pulsations at the $\delta \mathrm{H}$ component of the KAK ground station (a) and the positions of the CSES, VAP-A, and VAP-B in dipole-based coordinates with MLT (b) and MLAT (c) during 14:00-15:00 UT.

Figure 6 displays the comparison of $\mathrm{Pi} 2$ pulsations detected at the $\delta \mathrm{H}$ component at KAK and the compressional $\delta \mathrm{Bz}$ component at both the VAP-A and VAP-B satellites. The event UT, MLAT, and MLT are indicated at the bottom. It is clear that there are perturbations in VAP-B $\delta \mathrm{Bz}$, but their waveforms do not match $\delta \mathrm{H}$ with a small phase delay. On the other hand, VAP-A does not exhibit Pi2 oscillation, likely because VAP-A is close to the magnetic equator ( - $0.5 \mathrm{MLAT})$. Therefore, we will focus on the Pi2 wave detected by VAP-B. 


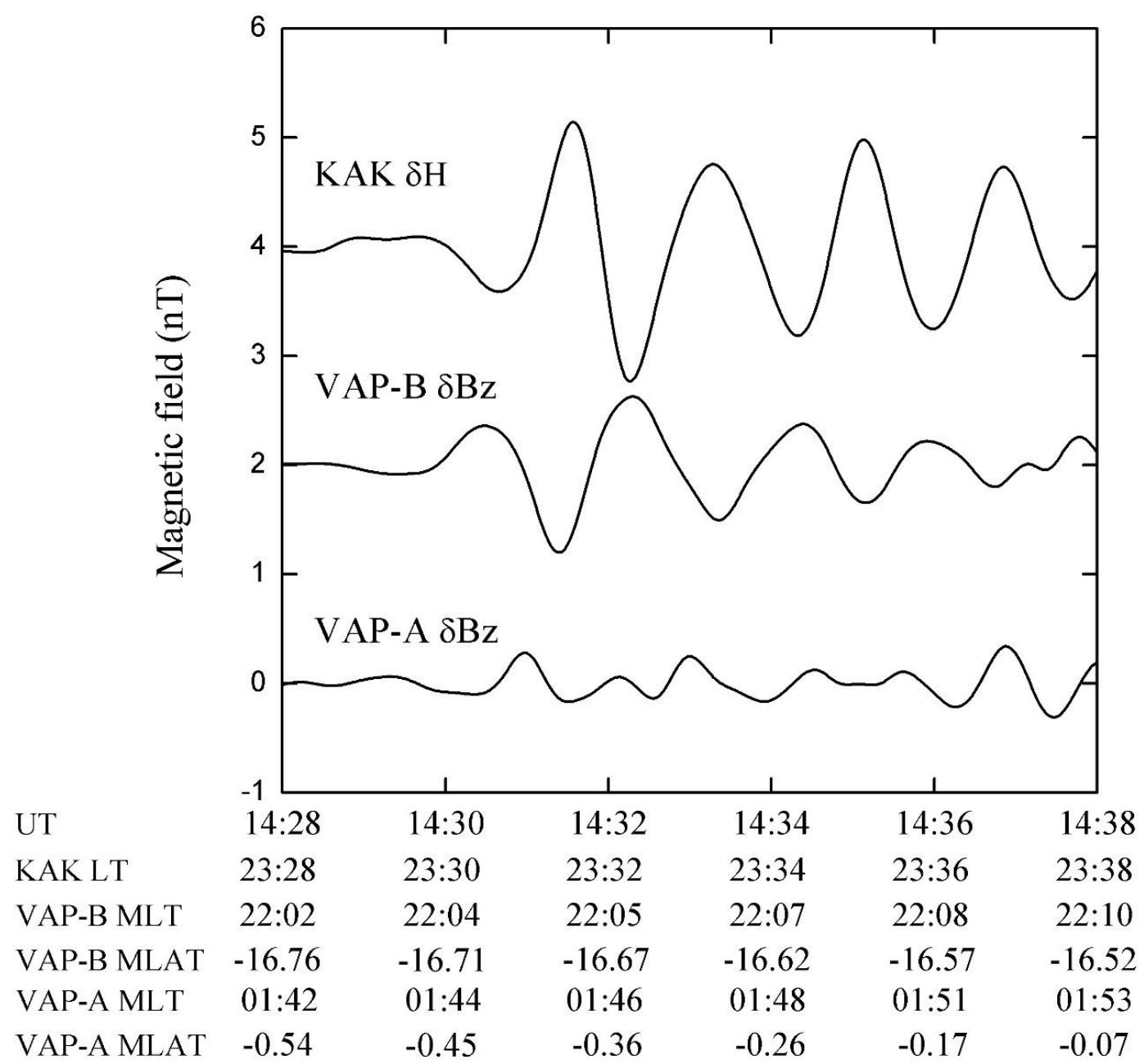

Figure 6. Comparison of $\mathrm{Pi} 2$ oscillations observed by the horizontal $\delta \mathrm{H}$ component at the KAK and the compressional $\delta \mathrm{Bz}$ component at both VAP-A and VAP-B satellites.

To check the correspondence between the Pi2 perturbations as observed by KAK, CSES, and VAP-B, we calculated the coherence, cross phase between KAK $\delta \mathrm{H}$, the CSES $\delta \mathrm{Bz}$, and the VAP-B $\delta \mathrm{Bz}$ during the time interval 14:30-14:40 UT. Figures 7 and 8 reveal the comparison of the time series and spectral characteristics of both KAK $\delta \mathrm{H} / \mathrm{VAP}-\mathrm{B} \delta \mathrm{Bz}$ and CSES $\delta \mathrm{Bz} / \mathrm{VAP}-\mathrm{B} \delta \mathrm{Bz}$, respectively. In Figures 7 and 8 , we noticed that $\delta \mathrm{Bz}$ components of VAP-B present oscillations that have a waveform similar to those of KAK and CSES with a time delay of $\sim 90 \mathrm{~s}$. The oscillations in the $\delta \mathrm{Bz}$ component were in phase. The calculated high-coherence spectral numbers of $\delta \mathrm{Bz}$ between CSES and VAP-B and $\mathrm{KAK} \delta \mathrm{H}$ and VAP-B $\delta \mathrm{Bz}$ are quite similar. Figures 7 and 8 confirm that the VAP-B and CSES Pi2s in the $\delta \mathrm{Bz}$ have quite a similar spectrum at $\sim 7.5 \mathrm{mHz}$ as that of the $\mathrm{KAK} \delta \mathrm{H}$ component on the ground. 

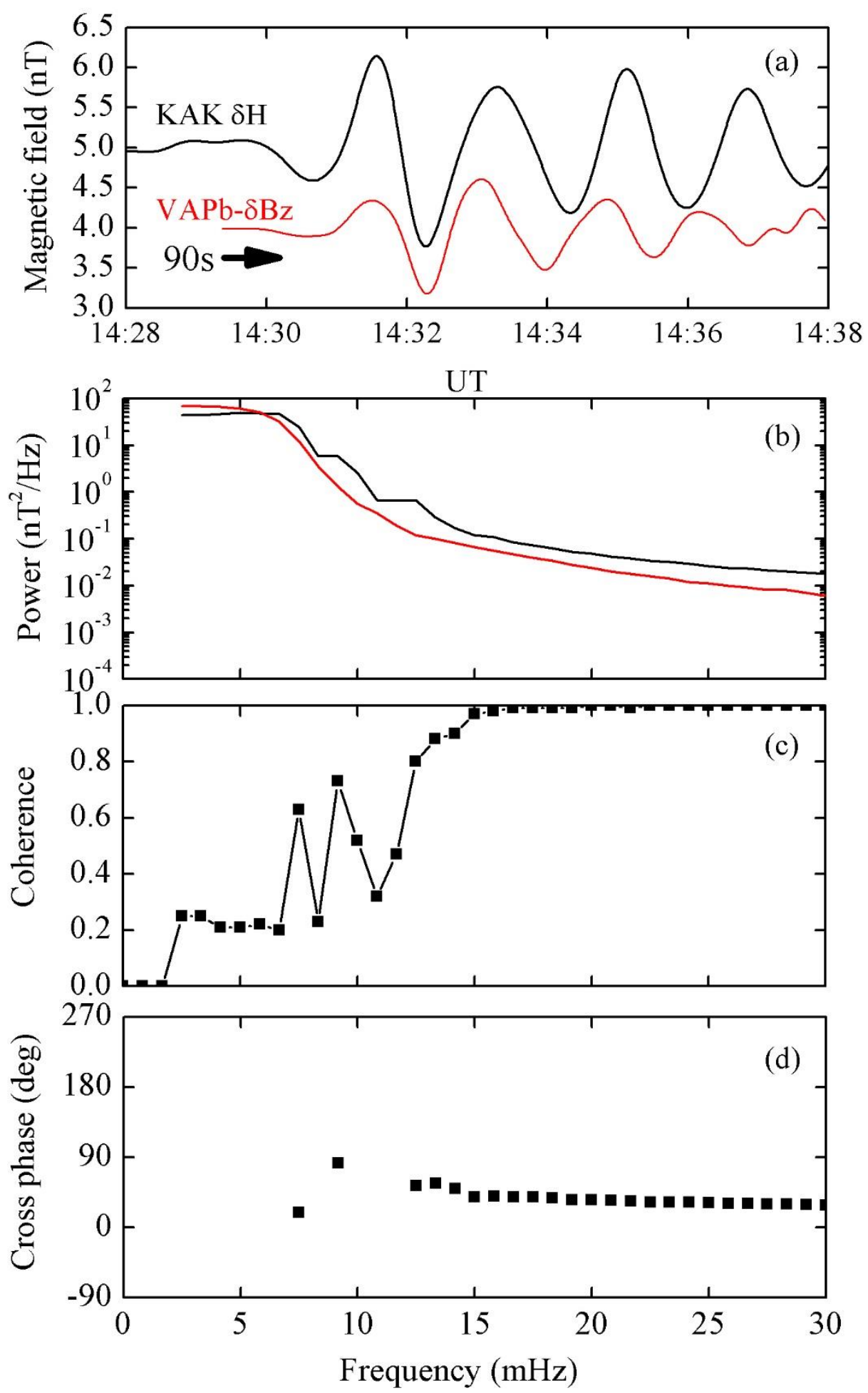

Figure 7. Comparison of (a) time series and (b-d) spectral characteristics of KAK $\delta \mathrm{H}$ and VAP-B $\delta \mathrm{Bz}$. 

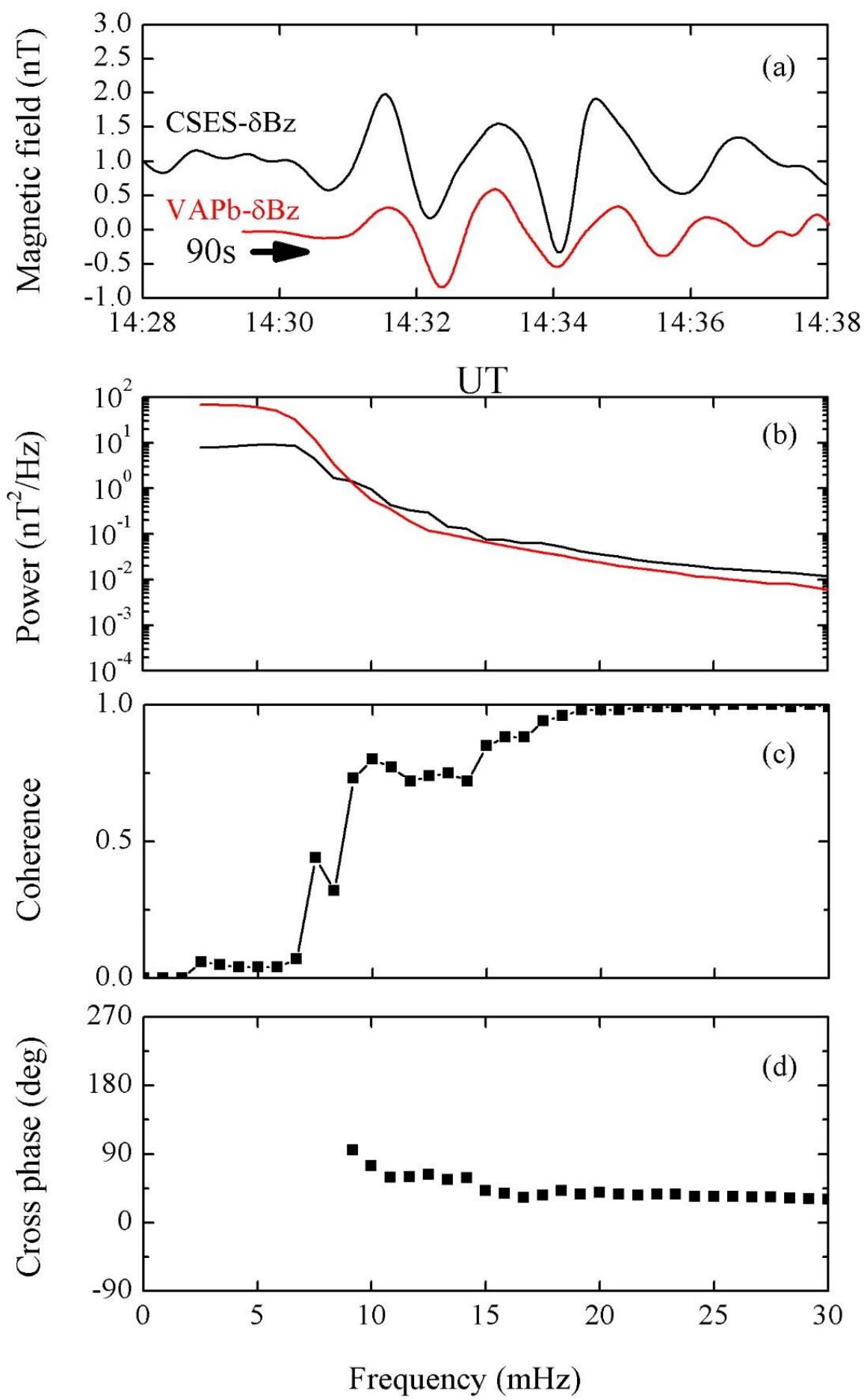

Figure 8. Comparison of (a) time series and (b-d) spectral characteristics of CSES $\delta$ Bz and VAP-B $\delta B z$.

\section{Discussion}

This paper reports, for the first time, the observation of a Pi2 event from the CSES satellite in the topside ionosphere. In previous studies and observations [35-37], the 3-D fluctuation current system of SCWs have been investigated. The authors of [38] reported the distribution of the two-dimensional (2-D) substorm system structure using AMPERE satellite data. According to [10,39], the first deflection in a Pi2 wave could be a proxy for the signature of the substorm current wedge, and the Pi2 wave 
displays deflections at the sub-storm onset [40]. This Pi2 pulsation initial deflection could be the signature of the onset time of the substorm current wedge [29].

The oscillations of the $\mathrm{KAK} \delta \mathrm{H}$ in a low latitude and the $\delta \mathrm{By}$ component in the topside ionosphere are in agreement with the SCW model, but at the same time, the $\delta$ By component displayed some phase shifts exhibited after the Pi2 onset (see Figure 2b). On the other hand, a 90 s phase shift during the Pi2 event is shown between the $\delta \mathrm{Bz}$ component oscillations at VAP-B in the plasmasphere with both the $\delta \mathrm{Bz}$ component at CSES and at the KAK $\delta \mathrm{H}$ (see Figures 7 and 8). As shown in Figures 3, 7 and 8, the $\mathrm{Pi} 2$ wave in the $\mathrm{KAK} \delta \mathrm{H}$ component has the same spectral peak at $\sim 7 \mathrm{mHz}$, with few phase differences, and with both $\delta \mathrm{Bz}$ components at CSES and VAP-B. The FLR model is not likely considered as a source of a Pi2 event because the frequency of a spectral peak was not different at the magnetosphere, ionosphere, and on the ground, so the driven Alfvénic waves generated by the fast wave mode is likely to be considered as valid. This behavior could be interpreted by the SCW, and we assume that the fast mode wave is the reason for the exhibition of the Pi2 wave at the $\mathrm{KAK} \delta \mathrm{H}$ component.

The SCW source mode and cavity mode have not been verified by several studies, while a few of them showed a coherent relationship. The authors of [41] showed that the behavior of SCW was detected in conjugate stations at a high latitude with plasma flow vortices of up to $900 \mathrm{~km} / \mathrm{s}$. These observations were in the premidnight region at the radial distance between 9 and $12 \mathrm{RE}$ and generated the FAC of the SCW at the substorm expansion phase onset time. The authors of [42] showed that the compressional pulse could modulate the SCW. Returning to Figure 1a, we notice that the substorm activity associated with our Pi2 pulsation was quite low. In the onset time of the Pi2 event, SML was $-25 \mathrm{nT}$. At the same time, the positive bay at KAK H was detected (see Figure 1b). It suggests that the SCW could be sufficient for exhibiting the magnetic bay signature in our Pi2 study.

Figure 2a,b show that the compressional oscillation detected at CSES in the topside ionosphere was observed at the same time with the horizontal component identified on the ground without time delay. Figure $2 \mathrm{~b}$ suggests that the first two cycles of the $\delta$ By component fluctuations were due to the SCW pulses. Power spectrum density almost has a similar pattern between $\delta \mathrm{H}$ and $\delta \mathrm{Bx} / \delta \mathrm{Bz}$, but not for $\delta \mathrm{H}$ and $\delta \mathrm{By}$ (Figure $3 \mathrm{a}-\mathrm{c}$ ). It suggests a different generation mechanism between $\delta \mathrm{Bx} / \delta \mathrm{Bz}$ and $\delta \mathrm{By}$.

During the Pi2 event, CSES moved rapidly from middle-latitude to the near-equatorial region (Figure 5). Magnetic perturbations of northern and southern FACs of SCW are almost canceled out in the equatorial latitude. The decay of CSES $\delta \mathrm{By}$ amplitudes was more rapid than those of $\delta \mathrm{Bx} / \delta \mathrm{Bz}$ (Figures 2 and 3). The higher frequency part of the $\delta$ By power was more attenuated than those of $\delta \mathrm{Bx} / \delta \mathrm{Bz}$. It could be due to the integrated effect of the fine-structured FACs [29]. This is consistent with what has been schematically illustrated by [11]. This scenario in the magnetosphere-ionosphere coupling system proposed that the Pi2 wave current system generated an AC circuit in this system [43].

The authors of [11] developed the magnetohydrodynamics (MHD) model to describe wave propagation. This model estimates the time delay from the satellite to the conjugate ionosphere as $\sim 50 \mathrm{~s}$. In our event, no time of flight is observed between the low latitude station and the ionosphere (Figure 2a,b). Observation shows that the periodicity characteristics of the dominant pulses between $\delta \mathrm{H}$ and $\delta \mathrm{By}$ corresponded to one another, although $\delta \mathrm{H}$ and $\delta \mathrm{By}$ have different decay patterns and spectrum signatures. This is a manifestation of global high-correlation Pi2 waves [11,29].

The same model of [11] also estimated the time of flight of the fast wave propagation from the near-Earth plasma sheet to Earth. They found that it was $\sim 60 \mathrm{~s}$ for the paths between the THEMIS satellites and equatorial ground station, Ancon (ANC, geomagnetic latitude $=-2.1^{\circ}$, geomagnetic longitude $=355.6^{\circ}$ ). The time of flight of the fast wave, identified in our event between the VAP-B satellite and KAK station, is $90 \mathrm{~s}$ (Figure 7). However, the displayed wave at the CSES was delayed by $90 \mathrm{~s}$ compared with those displayed in the magnetosphere (Figure 8). This lateness could be referring to the Alfvén wave propagation along the SCW [29].

Therefore, it is well known that the Pi2 oscillation is triggered first from the magnetosphere to the ionosphere by the Alfvén wave, which is considered responsible for FACs evolution [44,45], along with the initial SCW signal [29-47]. 


\section{Conclusions}

In this work, we report a Pi2 event observed by CSES satellite on 3 September 2018, at 14:30 UT. To the best of the authors' knowledge, this is the first investigation of a Pi2 pulsation made using the CSES satellite. The notable key findings of this study are the following:

(1) Pi2 observation and analysis confirm the consistency and reliability of the high precision magnetometer (HPM) equipped by two fluxgate magnetometers (FGM1 and FGM2) onboard CSES.

(2) The observed waveform in the compressional component at CSES is similar to that of the horizontal component at KAK, indicating the magnetospheric source of the Pi2 event.

(3) The Pi2 wave is seen in the azimuthal component at CSES with a high correlation with the ground horizontal component, which could be explained by the substorm current wedge (SCW).

(4) This interpretation is further confirmed by checking the compressional component of the Van Allen Probe B satellite inside the plasmasphere, which, for the first time, gives observational support for an earlier model of the three-dimension oscillations of the SCW associated with the Pi2 event as studied by [29].

With the interpretation of magnetic field data from different space sources in the magnetosphere, the ionosphere can help to better understand the propagation of Pi2 magnetic pulsation. Simultaneous Pi2 events recorded in several locations of the geospace are necessary, and LEO missions such as the CSES and Swarm satellites in the topside ionosphere, integrated with VAP, MMS, ERG (Arase), and GOES observations in the inner magnetosphere, as well as THEMIS observations in the plasma sheet, are expected to resolving many $\mathrm{Pi} 2$ issues that are still unclear. Moreover, the integration of space-based satellites with ground-based measurements can explain how Pi2 pulsation spread spatially.

Author Contributions: Conceptualization, E.G. and T.U.; Data curation, E.G. and D.M.; Formal analysis, E.G. and D.M.; Funding acquisition, A.Y.; Investigation, E.G. and D.M.; Methodology, E.G. and D.M.; Software, E.G. and D.M.; Writing - original draft, E.G. and D.M.; Writing - review \& editing, E.G., D.M., A.Y., T.U., A.D.S., L.P., X.S. and A.F. All authors have read and agreed to the published version of the manuscript.

Funding: This research work was funded by International Center for Space Weather Science and Education, Kyushu University, Japan.

Acknowledgments: E.G. would like to express his gratitude to the Egyptian Government for providing him a fellowship for visiting ICSWSE, Kyushu University, Japan. The geomagnetic field data from KAK were provided by Kakioka Magnetic Observatory (http://www.kakioka-jma.go.jp/). We gratefully acknowledge SuperMAG for SML index data (http://supermag.jhuapl.edu/) and Van Allen Probes Science Operations Centers located at University of Iowa (http://emfisis.physics.uiowa.edu) for Van Allen Probes magnetic data. W.K. is acknowledged for deriving electron density detected by Van Allen Probes. This work made use of the data from CSES mission, a project funded by China National Space Administration (CNSA) and China Earthquake Administration (CEA) in collaboration with Italian Space Agency (ASI) and Istituto Nazionale di Fisica Nucleare (INFN). We acknowledge also LIMADOU-Science Project funded by ASI and the project "The electromagnetic data validation and scientific application research based on CSES satellite" funded by ISSI-BJ under which some of the coauthors make active research. This work was supported by JSPS KAKENHI Grand Number JP20H01961 and JP15H05815.

Conflicts of Interest: The authors declare no conflict of interest.

\section{References}

1. Keiling, A.; Takahashi, K. Review of Pi2 models. Space Sci. Rev. 2011, 161, 63-148. [CrossRef]

2. Sutcliffe, P.R.; Yumoto, K. On the cavity mode nature of low latitude Pi2 pulsations. J. Geophys. Res. 1991, 96, 1543-1551. [CrossRef]

3. Ghamry, E. Morningside Pi2 pulsation observed in space and on the ground. J. Astron. Space Sci. 2015, 32, 305-310. [CrossRef]

4. Shinohara, M.; Yumoto, K.; Yoshikawa, A.; Saka, O.; Solovyev, S.I.; Vershinin, E.F.; Trivedi, N.B.; Da Costa, J.M.; The $210^{\circ}$ MM Magnetic Observation Group. Wave characteristics of daytime and nighttime Pi2 pulsations at the equatorial and low latitudes. Geophys. Res. Lett. 1997, 24, 2279-2282. [CrossRef]

5. Olson, J.V. Pi2 pulsations and substorm onsets: A review. J. Geophys. Res. 1999, 104, 17499-17520. [CrossRef] 
6. Allan, W.; Menk, F.; Fraser, B.; Li, Y.; White, S. Are low-latitude Pi2 pulsations cavity/waveguide modes? J. Geophys. Res. 1996, 23, 765-768. [CrossRef]

7. Takahashi, K.; Lee, D.H.; Nosé, M.; Anderson, R.R.; Hughes, W.J. CRRES electric field study of the radial mode structure of Pi2 pulsations. J. Geophys. Res. 2003, 108, 1210. [CrossRef]

8. Ghamry, E.; Kim, K.H.; Kwon, H.J.; Lee, D.H.; Park, J.S.; Choi, J.; Hyun, K.; Kurth, W.; Kletzing, C.; Wygant, J. Simultaneous Pi2 observations by the Van Allen probes inside and outside the plasmasphere. J. Geophys. Res. 2015, 120, 4567-4575. [CrossRef]

9. Ghamry, E. Pi2 pulsations during extremely quiet geomagnetic condition: Van Allen Probe observations. J. Astron. Space Sci. 2017, 34, 111-118. [CrossRef]

10. Baumjohann, W.; Glaßmeier, K. The transient response mechanism and Pi2 pulsations at substorm onset-Review and outlook. Planet. Space Sci. 1984, 32, 1361-1370. [CrossRef]

11. Uozumi, T.; Abe, S.; Kitamura, K.; Tokunaga, T.; Yoshikawa, A.; Kawano, H.; Marshall, R.; Morris, R.J.; Shevtsov, B.M.; Solovyev, S.I.; et al. Propagation characteristics of Pi2 pulsations observed at high- and low-latitude MAGDAS/ CPMN stations: A statistical study. J. Geophys. Res. 2009, 114, A11207. [CrossRef]

12. Uozumi, T.; Yumoto, K.; Tokunaga, T.; Solovyev, S.I.; Shevtsov, B.M.; Marshall, R.; Liou, K.; Ohtani, S.; Abe, S.; Ikeda, A.; et al. AKR modulation and Global Pi 2 oscillation. J. Geophys. Res. 2011, 116, A06214. [CrossRef]

13. Uozumi, T.; Yoshikawa, A.; Ohtani, S.; Imajo, S.; Baishev, D.G.; Moiseev, A.V.; Yumoto, K. Initial deflection of middle-latitude $\mathrm{Pi} 2$ pulsations in the premidnight sector: Remote detection of oscillatory upward field-aligned current at substorm onset. J. Geophys. Res. Space Phys. 2016, 121, 6324-6340. [CrossRef]

14. Ghamry, E.; Fathy, A. A new method to calculate the time delay of the Pi2 pulsations. Adv. Space Res. 2016, 57, 701-709. [CrossRef]

15. Fathy, A.; Ghamry, E.; Mahrous, S. Propagation of irregular magnetic pulsation using cross wavelet and maximum time energy methods. NRIAG J. Astron. Geophys. 2017, 6, 141-147. [CrossRef]

16. Imajo, S.; Yoshikawa, A.; Uozumi, T.; Ohtani, S.; Nakamizo, A.; Chi, P. Application of a global magnetospheric-ionospheric current model for dayside and terminator Pi2 pulsations. J. Geophys. Res. Space Phys. 2017, 122, 8589-8603. [CrossRef]

17. Pilipenko, V.; Fedorov, E.; Heilig, B.; Engebretson, M.J.; Sutcliffe, P.; Lühr, H. ULF waves in the topside ionosphere: Satellite observations and modeling, in the dynamic magnetosphere. In IAGA Special Sopron Book Series; Springer: Dodderek, The Netherlands, 2011; pp. 257-269.

18. Balasis, G.; Papadimitriou, C.; Daglis, I.A.; Pilipenko, V. ULF wave power features in the topside ionosphere revealed by Swarm observations. Geophys. Res. Lett. 2015, 42, 6922-6930. [CrossRef]

19. Heilig, B.; Sutcliffe, P.R. Coherence and phase structure of compressional ULF waves at low-Earth orbit observed by the Swarm satellites. Geophys. Res. Lett. 2016, 43, 945-951. [CrossRef]

20. Takahashi, K.; Hughes, W.; Anderson, R.; Solovyev, S. CRRES satellite observations associated with low-latitude Pi2 pulsations. J. Geophys. Res. 1999, 104, 17431-17440. [CrossRef]

21. Sutcliffe, P.R.; Lühr, H. A comparison of Pi2 pulsations observed by CHAMP in low Earth orbit and on the ground at low latitudes. Geophys. Res. Lett. 2003, 30, 2105. [CrossRef]

22. Han, D.S.; Iyemori, T.; Nose, M.; McCreadie, H.; Gao, Y.; Yang, F.; Yamashita, S.; Stauning, P. A comparative analysis of low-latitude Pi2 pulsations observed by Ørsted and ground stations. J. Geophys. Res. 2004, 109, A10209. [CrossRef]

23. Yang, Y.Y.; Zhima, Z.R.; Shen, X.H.; Chu, W.; Huang, J.P.; Wang, Q.; Yan, R.; Xu, S.; Lu, H.X.; Liu, D.P. The first intense geomagnetic storm event recorded by the China Seismo-Electromagnetic Satellite. Space Weather 2020, 18, e2019SW002243. [CrossRef]

24. Zhou, B.; Cheng, B.; Gou, X.; Li, L.; Zhang, Y.; Wang, J.; Magnes, W.; Lammegger, R.; Pollinger, A.; Ellmeier, M.; et al. First in-orbit results of the vector magnetic field measurement of the High Precision Magnetometer onboard the China Seismo-Electromagnetic Satellite. Earth Planets Space 2019, 71, 119. [CrossRef]

25. Piersanti, M.; De Michelis, P.; Del Moro, D.; Tozzi, R.; Pezzopane, M.; Consolini, G.; Marcucci, M.F.; Laurenza, M.; Di Matteo, S.; Pignalberi, A.; et al. From the Sun to the Earth: August 25, 2018 geomagnetic storm effects. Ann. Geophys. 2020, 38, 703-724. [CrossRef]

26. Marchetti, D.; De Santis, A.; Shen, X.; Campuzano, S.A.; Perrone, L.; Piscini, A.; Di Giovambattista, R.; Jin, S.; Ippolito, A.; Cianchini, G.; et al. Possible Lithosphere-Atmosphere-Ionosphere Coupling effects prior to the $2018 \mathrm{Mw}=7.5$ Indonesia earthquake from seismic, atmospheric and ionospheric data. J. Asian Earth Sci. 2020, 188, 104097. 
27. Yan, R.; Shen, X.; Huang, J.; Wang, Q.; Chu, W.; Liu, D.; Yang, Y.; Lu, H.; Xu, S. Examples of unusual ionospheric observations by the CSES prior to earthquakes. Earth Planet. Phys. 2018, 2, 515-526. [CrossRef]

28. Shen, X.; Zong, Q.G.; Zhang, X.M. Introduction to special section on the China Seismo-Electromagnetic Satellite and initial results. Earth Planet. Phys. 2018, 2, 439-443. [CrossRef]

29. Uozumi, T.; Yoshikawa, A.; Ohtani, S. Formation of a 3-D Oscillatory Current System Associated with Global High-Correlation Pi2 Event: A Case Study. J. Geophys. Res. Space Phys. 2020, 125, e2019JA02698. [CrossRef]

30. Finlay, C.; Olsen, N.; Kotsiaros, S.; Gillet, N.; Tøffner-Clausen, L. Recent geomagnetic secular variation from Swarm and ground observatories as estimated in the CHAOS-6 geomagnetic field model. Earth Planets Space 2016, 68, 112. [CrossRef]

31. Mauk, H.B.; Fox, N.J.; Kanekal, S.G.; Kessel, R.L.; Sibeck, D.G.; Ukhorskiy, A. Science objectives and rationale for the Radiation Belt Storm Probes mission. Space Sci. Rev. 2012, 179, 3-27. [CrossRef]

32. Kletzing, C.A.; Kurth, W.S.; Acuna, M.; MacDowall, R.J.; Torbert, R.B.; Averkamp, T.; Bodet, D.; Bounds, S.R.; Chutter, M.; Connerney, J.; et al. The Electric and Magnetic Field Instrument Suite and Integrated Science (EMFISIS) on RBSP. Space Sci. Rev. 2013, 179, 127-181. [CrossRef]

33. Newell, P.T.; Gjerloev, J.W. Evaluation of SuperMAG auroral electrojet indices as indicators of substorms and auroral power. J. Geophys. Res. 2011, 116, A12211. [CrossRef]

34. Newell, P.T.; Gjerloev, J.W. Substorm and magnetosphere characteristic scales inferred from the SuperMAG auroral electrojet indices. J. Geophys. Res. 2011, 116, A12232. [CrossRef]

35. Kamide, Y. The relationship between field-aligned currents and the auroral electrojets: A review. Space Sci. Rev. 1982, 31, 127-243. [CrossRef]

36. Fujii, R.; Offman, R.A.; Anderson, P.C.; Craven, J.D.; Sugiura, M.; Frank, L.A.; Maynard, N.C. Electrodynamic parameters in thenighttime sector during auroral substorms. J. Geophys. Res. 1994, 99, 6093-6112. [CrossRef]

37. Gjerloev, J.W.; Hoffman, R.A. The large-scale current system during auroral substorms. J. Geophys. Res. Space Phys. 2014, 119, 4591-4606. [CrossRef]

38. Murphy, K.R.; Mann, I.R.; Rae, I.J.; Waters, C.L.; Frey, H.U.; Kale, A.; Singer, H.J.; Anderson, B.J.; Korth, H. The detailed spatial structure of field-aligned currents comprising the substorm current wedge. J. Geophys. Res. Space Phys. 2013, 118, 7714-7727. [CrossRef]

39. Nishida, A. Possible origin of transient dusk-to-dawn electric field in the nightside magnetosphere. J. Geophys. Res. 1979, 84, 3409-3412. [CrossRef]

40. Sakurai, T.; McPherron, R.L. Satellite observations of Pi2 activity at synchronous orbit. J. Geophys. Res. 1983, 88, 7015-7027. [CrossRef]

41. Keiling, A.; Angelopoulos, V.; Runov, A.; Weygand, J.; Apatenkov, S.V.; Mende, S.; McFadden, J.; Larson, D.; Amm, O.; Glassmeier, K.H.; et al. Substorm current wedge driven by plasma flow vortices: THEMIS observations. J. Geophys. Res. 2009, 114, A00C22. [CrossRef]

42. Kepko, L.; Kivelson, M.G.; Yumoto, K. Flow bursts, braking, and Pi2 pulsations. J. Geophys. Res. 2001, 106, 1903-1916. [CrossRef]

43. Ohtani, S.; Uozumi, T. Nightside magnetosphere-ionosphere current circuit: Implications for auroral streamers and Pi2 pulsations. J. Geophys. Res. Space Phys. 2018, 123, 350-363. [CrossRef]

44. Southwood, D.J.; Kivelson, M.G. An approximate description of field-aligned currents in a planetary magnetic field. J. Geophys. Res. 1991, 96, 67-75. [CrossRef]

45. Kan, J.R.; Sun, W. Substorm expansion phase caused by an intense localized convection imposed on the ionosphere. J. Geophys. Res. 1996, 101, 27271-27281. [CrossRef]

46. Lester, M.; Hughes, W.J.; Singer, H.J. Polarization patterns of Pi2 magnetic pulsations and the substorm current wedge. J. Geophys. Res. 1983, 88, 7958-7966. [CrossRef]

47. Lester, M.; Hughes, W.J.; Singer, H.J. Longitudinal structure in Pi2 pulsations and the substorm current wedge. J. Geophys. Res. 1984, 89, 5489-5494. [CrossRef]

(C) 2020 by the authors. Licensee MDPI, Basel, Switzerland. This article is an open access article distributed under the terms and conditions of the Creative Commons Attribution (CC BY) license (http://creativecommons.org/licenses/by/4.0/). 